\title{
O dharma na impermanência da web: difusão e transformações do zen-budismo na internet (2015-2017)
}

\author{
Dharma in the impermanence of the web: dissemination and transformation \\ of zen-Buddhism on the internet (2015-2017)
}

Richard Gonçalves André*

\begin{abstract}
Resumo
No Brasil, com o envelhecimento e a morte dos primeiros imigrantes nipônicos, o Budismo étnico tem enfrentado desafios para sua perpetuação. Tendo em vista esse contexto histórico, o objetivo deste artigo é analisar a difusão do Zen Budismo no Youtube no período de 2015 a 2017, utilizando como fontes primárias os vídeos da Monja Coen, religiosa não descendente de japoneses que tem atuado no universo midiático nos últimos anos. Como metodologia, os vídeos são discriminados em diferentes categorias, sendo analisados tanto a partir de seus conteúdos quanto de sua composição audiovisual. Da perspectiva teórica, são utilizados os conceitos de representação e apropriação propostos, respectivamente, por Roger Chartier e Michel de Certeau. Como resultados, percebe-se que a divulgação do Zen na Web tem permitido que a religião consiga transcender as fronteiras étnicas, seja com a divulgação das ideias e práticas em português, seja com o diálogo com questões da sociedade atual.
\end{abstract}

Palavras-chaves: zen; budismo; Youtube.

\begin{abstract}
In Brazil, with the aging and death of the first Japanese immigrants, ethnic Buddhism has faced challenges for its perpetuation. Considering this historical context, this paper aims to analyze the diffusion of Zen Buddhism in Youtube in the period from 2015 to 2017, using as primary sources the videos of Monk Coen, monk nondescendant of Japanese who has been active in the media universe in recent years. As methodology, the videos are divided into different categories, being analyzed both from their contents and from their audiovisual composition. From the theoretical perspective, this paper uses the concepts of representation and appropriation proposed, respectively, by Roger Chartier and Michel de Certeau. As results, it is noted that the dissemination of Zen on the Web has allowed religion to transcend its ethnic borders, either through the dissemination of ideas and practices in Portuguese or through dialogue with current society issues.
\end{abstract}

Keywords: zen; buddhism; Youtube.

Artigo submetido em 14 de julho de 2017 e aprovado em 02 de setembro de 2018.

* Doutor em História. Professor da Universidade Estadual de Londrina (PR). País de origem: Brasil. E-mail: richard.historia@gmail.com 


\section{Introdução}

Num vídeo do Youtube, uma monja não descendente de japoneses, trajada com as vestes monásticas e com a cabeça raspada, oferece rápidas explicações sobre como realizar o zazen, literalmente a "meditação sentada" que constitui um dos pilares do Zen Budismoํ․ Entre outros aspectos, é ressaltado no material que, antes de sentar-se, o praticante deve fazer o gashô, uma saudação com as palmas das mãos juntas, inclinando-se em direção à imagem do Buda presente no recinto, assim como em relação aos demais meditadores. Feito isso, a pessoa senta sobre o zafu, espécie de almofada utilizada em práticas meditativas com o intuito de alcançar a postura adequada, cruzando as pernas normalmente ou em posição de lótus ou meia lótus. O zazen é realizado de olhos semiabertos, de forma que o indivíduo concentra-se na respiração abdominal ao longo de todo o processo. Após cerca de quarenta minutos (o que pode ser reduzido a até cerca de vinte minutos no caso de iniciantes, de acordo com a monja), é feito o kinhin, a caminhada lenta, compassada e respeitando o ritmo da respiração, durando aproximadamente oito minutos, que manteria o estado meditativo. Terminado o kinhin, o praticante deve realizar sentado mais uma sessão meditativa (NAMU, 2014).

Num ponto do vídeo, a monja chama a atenção para o valor de meditar em grupo (NAMU, 2014), lembrando que a comunidade (sangha) seria uma das três joias do Budismo, ao lado dos ensinamentos (dharma) e do próprio Buda (COHEN, 2008). Nesse momento, ela enfatiza um elemento relativamente novo, afirmando que "Talvez a gente possa ter práticas conjuntas virtuais. Por que não? Nós sabemos que há pessoas nas suas casas. E sei lá, pelo Skype, de alguma forma, nós estamos nos comunicando. Dizendo 'vamos fazer zazen agora'.” (NAMU, 2014). Na história do Zen ou, numa escala mais ampla, do Budismo como um todo, a sangha dizia respeito a uma comunidade religiosa, leiga ou ambas de caráter material (em oposição, aqui, ao virtual), geralmente circunscrita a certas fronteiras étnicas, cujos limites têm se ampliado em razão da difusão das vertentes e escolas budistas em diferentes regiões do mundo, acomodando-se em culturas marcadas por distintas

${ }^{1}$ Mais adiante, será explicado o que é o Zen Budismo e algumas de suas práticas. 
estruturas religiosas. A monja, no caso, expande a interpretação do fenômeno problematizando as fronteiras, até então espaciais e étnicas, alargadas agora para a esfera virtual.

O nome da monja em questão é Cláudia Coen, tendo sido ordenada na Escola Sôtô Zen². Ela desempenha o papel, desde meados da década de 1990, de difundir o Budismo não apenas entre o público descendente de japoneses, como também entre não descendentes (USARSKI, 2002). Atualmente, ela é uma figura popular nos meios de comunicação brasileiros, aparecendo em diversos vídeos na Internet, em documentários (como no filme intitulado "O eu maior" [2012], dirigido por Fernando Schultz e Paulo Schultz), em entrevistas televisivas, entre outras manifestações. Tendo em vista essas questões, o presente artigo busca compreender, a partir da atuação da Monja Coen, a difusão virtual do Budismo considerando o processo de desenvolvimento dessa religião no Brasil, que teria passado, de acordo com Frank Usarski (2002), por etapas como os chamados Budismo de imigração e de conversão. Como hipótese, propõe-se aqui que a virtualização do dharma, no caso do Zen, constitui um dos canais para sua expansão para além das fronteiras étnicas relacionadas aos imigrantes e descendentes de japoneses no país, passando a dialogar com novas questões e ressignificando, portanto, elementos religiosos pertencentes a seu repertório.

Como fontes, são utilizados os vídeos publicados pelo canal MOVA no Youtube que têm como foco a atuação da Monja Coen, disponibilizados entre 2015 e 2017 e que continuam em produção. Do ponto de vista metodológico, são utilizadas as proposições de Marcos Napolitano (2011), que sugere procedimentos relacionados à análise de documentos audiovisuais. Além da contextualização histórica, atinando para aspectos como espaço e tempo, as razões que perpassam a produção e o público para o qual a narrativa é destinada, é preciso também chamar a atenção para os elementos de composição da obra audiovisual, como a disposição dos objetos na cena, as interliguagens, a sonoridade, entre outros pontos. Não se

\footnotetext{
${ }^{2}$ Sôtô Zen é uma das subescolas do Zen, tendo sua ênfase voltada para as práticas meditativas (SUZUKI, 2005).
} 
tratam apenas de questões técnicas, mas de linguagens fundamentais para a construção dessa categoria heurística.

Ainda no tocante à metodologia, é preciso também considerar que os vídeos são postados com certa regularidade na Internet, de forma que o meio de acesso implica questões importantes para o pesquisador. O material pode ser visualizado por meio de diferentes dispositivos, como desktops, laptops, tablets e smartphones, não se reduzindo, portanto, a formas específicas de acesso. Isso gera diferentes práticas de leitura (CHARTIER, 2002), em sentido lato, na medida em que o leitor pode realizar a apropriação em variados espaços e tempos, desde aquele que assiste os vídeos na comodidade de sua residência àquele que o visualiza no ônibus com o celular em mãos3. Além disso, os vídeos postados no Youtube permitem o acesso a dados significativos para o pesquisador, como o canal de publicação, a data de postagem e a quantidade de visualizações dos materiais, o que permite analisar algumas formas de apropriação.

O fato de vídeos sobre o Zen serem publicados num canal do Youtube traz implicações teóricas significativas. Trata-se de uma religião, como será discutido mais adiante, que possui cerca de nove séculos no Japão, isso para não falar de seus antecedentes chineses e indianos. A Web é um meio que permite a flexibilização dos conteúdos postados, de forma que a Monja Coen tem discutido questões que, anteriormente, não pertenciam ao repertório doutrinário da religião, como o diálogo inter-religioso, questões terapêuticas e problemas sociais. Isso remete à dinâmica do fenômeno religioso do ponto de vista histórico, na medida em que as transformações não devem ser vistas, necessariamente, como corruptelas das crenças e práticas originais, mas transformações inerente às relações históricas entre religião e sociedade.

Nesse sentido, utiliza-se aqui o conceito de flexibilidade criativa (ANDRÉ, 2016), pressupondo que as mudanças históricas no repertório religioso não seriam

\footnotetext{
${ }^{3} \mathrm{~A}$ apropriação diz respeito à forma como os leitores, de modo ativo, recebem o texto, ressignificando-o e construindo sentidos às vezes imprevisíveis para os autores. No entanto, para Certeau, o texto transcende sua definição propriamente linguística, envolvendo também dimensões como a organização urbana, os discursos televisivos e as receitas culinárias (CERTEAU, 2014).
} 
entraves à manutenção de tradições ilusoriamente vistas como estáticas (HOBSBAWM, 2014), mas condições para sua perpetuação ao longo do tempo, tendo em vista, principalmente, sociedades receptoras que não dispõem das mesmas características históricas daquelas em que as religiões e as religiosidades foram "originalmente" gestadas. Isso é particularmente relevante no que se relaciona ao Budismo no Brasil, uma vez que diferentes escolas japonesas foram trazidas para o país por meio da imigração nipônica a partir de 1908, tendo sido institucionalmente estabelecidas, de forma geral, a partir dos anos 1950 (USARSKI, 2002; GONÇALVES, 2002; MATSUE, 2002; ROCHA, 2002). No entanto, um dos maiores obstáculos enfrentados pelas instituições budistas tem sido a progressiva morte dos japoneses e descendentes de primeira geração, ao passo que a oferta religiosa de caráter étnico, com ritos geralmente ministrados em japonês e circunscritos a uma esfera restrita do público, possui pouco potencial atrativo para as demais gerações e, também, para os não descendentes (ANDRÉ, 2016). Diante do quadro, nos últimos anos, essas escolas têm flexibilizado o discurso e as práticas religiosas, dialogando com novos aspectos e lançando mão, em alguns casos, dos meios de comunicação, inclusive virtuais, para o desenvolvimento de estratégias mais eficazes de proselitismo. É justamente essa flexibilidade que tem criado condições para a reprodução social do Budismo japonês no Brasil.

\section{A flexibilidade criativa do zen}

Antes de focar a atenção sobre a difusão e a transformação do Zen no Brasil por meio da Internet, é importante delinear as principais concepções e práticas da religião. O Zen foi introduzido no Japão durante o século XIII por monges como Eisai e Dôgen que, insatisfeitos com o elitismo do Budismo japonês preponderante no período, buscaram na China o que consideravam manifestações mais "puras" da religião quando comparadas à degeneração, de acordo com eles, do dharma presente no país durante o contexto histórico em questão (GONÇALVES, 1971; ALBUQUERQUE, 1997). 
Um dos elementos centrais do Budismo é a busca pela Iluminação, embora a definição do fenômeno possa variar de acordo com as diferentes escolas, com o objetivo de libertar-se do Samsara, isto é, o círculo vicioso de mortes e renascimentos que lançaria todos os seres numa espiral de sofrimento ${ }^{4}$. As variadas vertentes budistas propuseram métodos ou caminhos distintos para alcançar o estado iluminado. Algumas delas, de caráter recitativo, como as escolas de Terra Pura, enfatizam a importância da recitação do Nenbutsu como mecanismo para o renascimento na Terra Pura (Jôdo), que pode ser tanto interpretada como local físico para a prática do dharma quanto como metáfora para a Iluminação propriamente dita (BUDISMO, 2013).

O Zen, por sua vez, mais especificamente a Escola Sôtô Zen, ressalta a prática da meditação como caminho para a Iluminação. O zazen, como afirmado, é voltado para a tentativa de não se apegar aos pensamentos, deixando-os fluir e evitando maiores elaborações intelectuais, que seriam fruto da ignorância fundamental e que distorceriam a realidade, criando a ilusão de um eu provido de substância essencial e distinto do restante do universo. Sentar-se em zazen permitiria ao praticante alcançar, em determinado momento, um estado denominado samadhi, esquecendo-se absolutamente de si próprio, condição para alcançar a Iluminação (SEKIDA, 2008), voltada, no Sôtô Zen, para o contato com a realidade independentemente das estruturas sígnicas construídas ao longo da existência. Os sentidos seriam fonte de ilusão, permitindo a criação de conceitos lógicos que obscureceriam a natureza essencialmente ilógica do real5. Por isso, certas escolas do Zen, como o Rinzai, baseiam-se na reflexão a partir dos koan,

\footnotetext{
${ }^{4}$ Embora comum a praticamente todas as escolas budistas, a definição dos conceitos de lluminação e Samsara varia de forma significativa entre elas. Em relação ao primeiro, no caso da escola indiana Theravâda, a lluminação envolvia o desenvolvimento de habilidades como a retrocognição das vidas anteriores, o despertar de habilidades especiais (os sidhis, como a telecinese) e a possibilidade de enxergar o karma (o princípio de causa e efeito) inerente a todos os seres (COHEN, 2008). Escolas como o Zen, por sua vez, não discorrem acerca desses elementos, ressaltando, por outro lado, que a lluminação seria a possibilidade de entrar em contato com o mundo tal como ele é, independentemente da influência enganosa gerada pelos seis sentidos, incluindo a mente (SUZUKI, 2005). Quanto ao Samsara, no Theravâda o conceito pode ser compreendido como o círculo de mortes e renascimentos ao qual todos os seres estariam sujeitos (COHEN, 2008). As escolas japonesas, por sua vez, possuem pouca ênfase sobre a questão do renascimento em outras vidas (GONÇALVES, 2002), como será discutido mais adiante.

${ }^{5}$ A rigor, a questão da ignorância, de acordo com o Budismo, estaria inserida nos chamados Doze Elos de Originação Dependente, círculo sem início e fim delimitados e que levariam ao processo de Samsara. O ciclo seria marcado por elementos como a 1) ignorância, que levaria às 2) volições mentais, à 3) formação da consciência, à 4) constituição do corpo (nome e forma), aos 5) sentidos, ao 6) contato com o mundo fenomênico, às 7) inclinações pessoais, ao 8) desejo, à 9) ação contaminada, à 10) visão de mundo, 11) às circunstâncias de vida e, por fim, 12) ao envelhecimento e à morte (DALAI LAMA, 2011).
} 
situações ou frases paradoxais que, portanto, não possuiriam solução lógica, tais como "se encontrar o Buda, mate o Buda" e "o corvo não é negro" (SUZUKI, 2005; SEKIDA, 2008).

Não obstante a complexidade do Zen, ele tornou-se popular no Japão a partir do século XIII, juntamente com as escolas da Terra Pura e do Budismo Nichiren, em função da "simplicidade" do método para alcançar a Iluminação, isto é, sentar-se em silêncio e meditar (GONÇALVES, 1971) ${ }^{6}$. Não é casual que Murillo Nunes de Avezedo, um dos primeiros praticantes não descendentes do Zen no Brasil, denomine o Zen como "caminho direto" (AZEVEDO, 2005, p. 33). Não constitui objetivo do presente artigo realizar uma história do Zen desde sua estruturação no Japão à atualidade, na medida em que isso implicaria numa busca vazia pelas origens. Por ora, é importante salientar que, quando da vinda dos primeiros imigrantes japoneses para o Brasil, os três principais ramos trazidos por esse "Budismo de imigração", de acordo com Usarski (2002), foram o Zen, a Verdadeira Escola da Terra Pura e o Nichiren7.

No Brasil, o Budismo de imigração diz respeito às concepções e às práticas religiosas trazidas para o país pelos primeiros imigrantes (USARSKI, 2002) e, a princípio, mais ou menos circunscritas às fronteiras étnicas. A partir da segunda metade do século XX, diferentes escolas budistas começaram a passar por um processo de institucionalização, contando, progressivamente, com a construção de templos reconhecidos pelas sedes nipônicas e a presença de monges de formação, sobretudo japoneses (MAEYAMA, 1967). Pode-se dizer que se forma, progressivamente, as condições para a constituição de um campo religioso budista no Brasile, como percebem pesquisadores como Leonardo Henrique Luiz (2017) no que se relaciona à análise do processo de acomodação e estruturação da Verdadeira

\footnotetext{
${ }^{6}$ O Nichiren, também fundado no Japão no século XIII, é uma escola budista voltada para a recitação do Daimoku como forma de alcançar a lluminação (NAKAMAKI, 2002).

${ }^{7}$ A Verdadeira Escola da Terra Pura, também concebida no século XIII japonês, também constitui um ramo recitativo do Budismo. Baseia-se na recitação do Nenbutsu, sendo uma releitura feita pelo Monge Shinran a respeito das ideias do fundador da Escola da Terra Pura no país, Hônen (BUDISMO, 2013).

${ }^{8} \mathrm{O}$ campo seria um lugar institucional perpassado de regras mais ou menos estáveis, como é o caso das religiões organizadas que possuem concepções e práticas relativamente circunscritas. Isso permitiria que determinados campos se diferenciassem de outros no tocante à sua oferta religiosa, distinguindo-se, também, de formas de religião ainda não organizadas institucionalmente (BOURDIEU, 2005).
} 
Escola da Terra Pura em Londrina (PR). No caso da escola Sôtô Zen, na década de 1950 foram construídos os três primeiros templos no Brasil: o Zengenji em Mogi das Cruzes (SP), o Tokozan Busshinji em Rolândia (PR) e o Busshinji na grande São Paulo, situado no Bairro da Liberdade (marcado, no período, pela presença de japoneses e descendentes, entre outras etnias), tornando-se a sede da Sôtô Zen na América do Sul (ROCHA, 2002).

De forma geral, desde os anos 1950 até a atualidade, um dos principais problemas enfrentados pelas escolas budistas japonesas no Brasil diz respeito às condições para sua manutenção no país. É válido ressaltar que a maioria das instituições ao longo do tempo tem mantido o corpo monástico composto por japoneses ou descendentes falantes da língua japonesa, falando pouco (ou desconhecendo) o português. Os ritos, portanto, têm sido majoritariamente realizados em japonês, tendo em vista que as recitações são feitas de acordo com as tradições nipônicas. Os materiais, igualmente, são escritos em japonês. Portanto, com exceções mais ou menos bem sucedidas como o Zen, como será demonstrado mais adiante, o Budismo de origem japonesa tem permanecido sobretudo étnico (USARSKI, 2002).

O quadro, por outro lado, contrasta com a diminuição significativa dos falantes de japonês mesmo entre descendentes (SUZUKI, 1969), na medida em que os canais que permitiriam a manutenção da língua estariam desaparecendo. Isso dificultaria a perpetuação da religião entre a segunda e a terceira gerações, havendo, nas estatísticas realizadas por Teiti Suzuki (1969) ao longo dos anos 1960, uma correlação diretamente proporcional entre a diminuição de falantes de japonês e o decréscimo da prática das religiões nipônicas, dentre elas as diferentes modalidades do Budismo. No Japão, a "transmissão" linguística e religiosa repousava num habitus, utilizando novamente um conceito de Bourdieu (200o), longamente estabelecido e que dispensava maiores esforços no sentido de sua reprodução social 9 . No Brasil, considerando que esse habitus permaneceu restrito à

\footnotetext{
${ }^{9} \mathrm{O}$ habitus seria o conjunto de práticas naturalizadas ao longo do tempo, mas que seria fruto, a princípio, tanto de construções em determinados contextos históricos quando de conflitos simbólicos no sentido de estabelecê-las hegemonicamente (BOURDIEU, 2000).
} 
primeira geração, tem havido certa descontinuidade nas práticas linguísticas e religiosas entre as demais gerações, falantes do português (diferentemente de seus pais e avós) e que passaram a envolver-se com outros repertórios religiosos, principalmente as diferentes vertentes do Cristianismo (LUIZ, 2017).

Somada a isso, pode-se ressaltar, também, a morte dos japoneses de primeira geração (ANDRÉ, 2011). Por outro lado, como afirmado, certos templos têm permanecido com uma estrutura demasiadamente étnica e voltada de forma ainda precária para o proselitismo entre não descendentes (USARSKI, 2002). Isso tem gerado, nas últimas décadas, uma diminuição de público entre certas escolas budistas, uma vez que praticantes em potencial passaram a frequentar religiões japonesas mais abertas no tocante às fronteiras étnicas, como é o caso da Seichôno-ie (ALBUQUERQUE, 1999) ${ }^{10}$. Considerando a situação, pesquisadores como Usarski (2002) e Gonçalves (2002) têm ressaltado que o Budismo de imigração estaria em crise, demandando por diferentes práticas com o intuito de firmar-se para além do círculo étnico nipônico.

Nesse processo histórico, o Zen desempenha papel particularmente complexo. No caso do templo Busshinji, na grande São Paulo, desde sua estruturação institucional, ele passou, por um lado, a atender às demandas religiosas de japoneses e descendentes, tornando-se a sangha local. Um dos principais atrativos diz respeito aos ritos mortuários, como velórios e cerimônias periódicas, na medida em que, no Japão, o Budismo, principalmente a partir do início do século XVII, assumiu o caráter de religião especializada na lide com a morte (ANDRÉ, 2011). Nesse sentido, o Zen não diferia em grande medida de outras escolas no Brasil, como a Verdadeira Escola da Terra Pura e o Nichiren, voltadas para o patrimônio étnico nipônico.

Por outro lado, a prática fundamental do Sôtô Zen, como ressaltado, é o zazen, que passou a atrair um público não descendente por motivos variados.

\footnotetext{
${ }^{10}$ A Seichô-no-ie é uma religião japonesa criada na década de 1930 por Masaharu Taniguchi. Embora não possa ser considerada propriamente budista, ela hibridiza alguns de seus elementos com outras religiões, como o próprio Cristianismo (ALBUQUERQUE, 1999).
} 
Pode-se ressaltar elementos como a popularização, no Ocidente, do Zen por intermédio dos textos de Daisetz Teitaro Suzuki (2005), a princípio escritos em inglês e posteriormente traduzidos para o português. Até então, o conhecimento a respeito da religião era circunscrito aos monges e aos iniciados, geralmente pertencentes ao círculo étnico nipônico. Essa difusão encontrou uma conjuntura histórica fértil a partir dos anos 1950 em países como Estados Unidos e Inglaterra (e, por consequência, também no Brasil), marcados por movimentos de contracultura, que postulavam a rebeldia contra os valores hegemonicamente estabelecidos por meio da utilização de substâncias psicoativas como o LSD e as práticas meditativas orientais (WATTS, 1988). Pode-se acrescentar, ainda, a busca por uma religiosidade diferente daquela pregada pelas matrizes judaico-cristãs (ALBUQUERQUE, 1999), que encontrou no Zen terreno relativamente prolífico. Essa conjuntura de apropriação sugere a flexibilidade criativa do Budismo japonês, que sofre transformações ao ser praticado por grupos ocidentais que passaram a associá-lo com novos elementos, como o uso das substâncias psicoativas.

Retornando ao caso do Zen no Brasil, a partir da segunda metade do século $\mathrm{XX}$, alguns praticantes não descendentes de japoneses passaram a procurar as práticas de meditação realizadas no Templo Busshinji, sob a supervisão, então, do monge japonês Ryohan Shingu (ALBUQUERQUE, 2002). Alguns dos mais conhecidos praticantes seriam R. M. Gonçalves, professor do Departamento de História da Universidade de São Paulo (USP) e que iria se tornar, como afirmado, um dos principais pesquisadores do país sobre o Budismo e, também, monge pela Verdadeira Escola da Terra Pura (GONÇALVES, 2002); o engenheiro M. N. de Azevedo, que atuaria como tradutor de uma das principais obras de Suzuki, "Introdução ao Zen Budismo" (USARSKI, 2002; GONÇALVES, 2002) e, por fim, Eduardo Basto de Albuquerque, na época graduando em História pela USP e que, mais tarde, seria professor do Departamento de História da Universidade Estadual Paulista (UNESP) (USARSKI, 2002; ROCHA, 2002).

O perfil dos praticantes não descendentes do Zen no Brasil, o que começou a ser delineado já nessa primeira geração em torno do mestre Shingu, parece 
permanecer relativamente o mesmo até a atualidade. Como ressalta a antropóloga Cristina Moreira da Rocha (2002), apesar das diferenças individuais, haveria certas características mais ou menos comuns: 1) os praticantes pertenceriam a classes médias e altas da sociedade, desempenhando, sobretudo, o papel de profissionais liberais; 2) teriam certo grau de instrução, sendo geralmente universitários ou profissionais já formados que descobriram o Zen por intermédio de livros; 3) seriam pessoas que tiveram contato com outras religiões, inserindo seu encontro com a meditação como forma de busca espiritual e 4) seriam relativamente avessos às formas propriamente institucionais de religião. Porém, atualmente, é possível acrescentar um quinto elemento de perfil intuído por Rocha (2002, p. 246) ao referir-se à cybersangha, isto é, a sangha existente na Internet por meio de sites e fóruns de discussão. Contudo, pode-se ressaltar a função desempenhada pelo Youtube, criado em 2005, no sentido de difundir o Zen não apenas para além do círculo étnico, mas também transcendendo as fronteiras propriamente físicas, o que remete ao papel da Monja Coen.

\section{0 zen nos fios da web}

A própria Monja Coen, que antes de ascender à condição monástica chamava-se Cláudia Dias Baptista de Souza, encaixa-se no perfil delineado por Rocha (2002) sobre os praticantes do Zen no Brasil. A julgar pelas inúmeras viagens que realizou ao longo de sua vida laica (Suécia, Estados Unidos e Japão), ela pertence a uma família de classe média, possuindo, além disso, alto grau de instrução, tendo atuado como repórter no Jornal da Tarde. Inclusive, quando ainda jovem, relata que teria sido presa na Suécia por levar, junto com o namorado, LSD para o país, chamando a atenção para a ideia segundo a qual a substância psicoativa permitiria alcançar níveis mais profundos de consciência, possibilitando ao usuário sentir-se uno com a existência (ESSELIN, 2017). Com o tempo, ela teria percebido que seria possível alcançar esferas conscienciais profundas sem a utilização de substâncias psicoativas, como por intermédio do zazen (ESSELIN, 2017). 
Pode-se conjecturar, também, que Cláudia tenha percebido a adesão ao Zen como forma de busca espiritual, também conforme o perfil delineado por Rocha (2002). Como sugerido num documentário autobiográfico publicado no Youtube (FLEURY; MOVA FILMES, 2017), Cláudia teria iniciado suas práticas no Zen e, posteriormente, iniciado seu processo de ordenação religiosa na cidade norteamericana de Los Angeles. Vinda de uma família católica, sua mãe teria estranhado, a princípio, sua nova adesão espiritual, pensando que os monges houvessem realizado algum tipo de lavagem cerebral em sua filha, embora tenha aceitado a opção posteriormente concebendo que Cláudia estaria realizando os princípios cristãos por meio do Budismo. Dando continuidade ao treinamento monástico, Coen teria viajado para o Japão, retornando ao Brasil por volta de 1995 com o intuito de assumir a frente do Templo Busshinji (FLEURY; MOVA FILMES, 2017). Percebe-se, portando, um processo de busca espiritual de uma católica, que sai do uso juvenil do LSD e chega ao encontro com o Zen nos EUA e no Japão. Um dos elementos desviantes, todavia, em relação ao perfil sugerido por Rocha seria o desejo de Cláudia de tornar-se parte do corpo monástico, em detrimento da indisposição institucional de alguns praticantes do Zen no Brasil.

A formação de uma monja não descendente de japoneses, mas que possuía capital religioso no tocante ao Zen (falando o português e o japonês) seria importante no tocante ao processo de acomodação da religião no Brasil, lembrando que Coen teria assumido o Templo Busshinji em 1995, quando de seu retorno do Japão. Nos anos 1960, a primeira geração de praticantes não ocidentais do Zen em São Paulo, sob a supervisão do Monge Shingu, teria sofrido com a distância linguística (com exceção, talvez, de figuras como R. M. Gonçalves, que haviam aprendido japonês), como ressalta E. B. de Albuquerque (2002) em relato sobre sua experiência no Busshinji. Além disso, como sugerido, havia uma divisão entre os adeptos japoneses, imigrantes e descendentes que buscavam o templo como forma de cumprir as demandas mortuárias, e os praticantes não descendentes, que procuravam práticas como o zazen com o intuito de dar vazão às suas escolhas espirituais (ROCHA, 2002). Como forma de tentar superar o que era percebido por alguns (GONÇALVES, 2002) como uma crise do Budismo no Brasil, adotou-se uma 
progressiva política no templo de atrair o público não descendente. Isso talvez tenha se consolidado de fato apenas com a chegada da Monja Coen. Sendo não descendente de japoneses e falando as duas línguas, além de possuir toda formação monástica legitimada pelas instituições norte-americanas e japonesas, a monja teve condições satisfazer as demandas dos dois grupos e minimizar possíveis conflitos internos (USARSKI, 2002).

Desde que assumiu a frente do Templo Busshinji, uma característica marcante da Monja Coen, e que também diz respeito a outros líderes religiosos no meio budista ou ligados a diferentes religiões, diz respeito ao papel ativo desempenhado em variadas mídias. Ela tem concedido entrevistas a jornais e revistas de ampla circulação como "O Estado de São Paulo” (VALLERIO, 2009), “El país” (NOVAES, 2016), “Veja” (MOHERDAUI, 2006) e “Cláudia” (ESSELIN, 2017); também tem aparecido em programas como "Mais você", da Rede Globo (2017), e "Provocações", da Rede Cultura (2016); no cinema, foi uma das figuras de destaque no documentário “O eu maior” (2012); tem realizado, além disso, palestras em diferentes cidades, como Curitiba (PR), São Paulo (SP) e Salvador (BA).

Os meios citados são apenas uma pequena amostra da escala midiática em que a Monja Coen tem atuado. Essa inserção, em parte, tem contribuído para a construção de um capital religioso e, portanto, de um carisma em torno de sua figura, envolvendo-se em discussões "deste mundo" (como os eventos políticos que repercutiram no impeachment da ex-presidente Dilma Rousseff (NOVAES, 2016) ${ }^{11}$. Isso a torna, provavelmente, a personagem budista mais conhecida do Brasil na atualidade, inclusive nos círculos não budistas, mas que, possivelmente, nela reconhecem autoridade religiosa.

A inserção midiática da Monja Coen começou a ocorrer, também, no Youtube em diferentes canais, como no MOVA. Os vídeos selecionados como fonte neste artigo fazem parte da série "Monja Coen responde", totalizando, até 5 de julho de 2017, oitenta e seis produções de cerca de cinco minutos cada. O canal

\footnotetext{
${ }^{11} \mathrm{O}$ capital religioso diz respeito à autoridade reconhecida em torno de algum indivíduo inserido no campo religioso, autorizando-o a proferir discursos com efeito de verdade (BOURDIEU, 2005).
} 
posta também outras gravações, como as palestras proferidas pela religiosa, de tempo consideravelmente mais longo, por volta de uma hora, mas que não serão abordadas nesta pesquisa.

A opção heurística aqui realizada justifica-se em razão dos vídeos da série "Monja Coen responde", tendo em vista sua duração diminuta, serem mais visualizados pelos internautas, facilitando, além disso, seu compartilhamento e acesso por meio de diferentes hardwares como computadores de mesa, notebooks, smartphones, tablets, videogames, smart TVs e outros dispositivos que permitam conexão à Internet. Os meios virtuais também podem variar, tais como o Facebook, o Whatsapp e outras redes sociais. Além disso, considerando a relativa expansão da rede sem fio no Brasil, não apenas wifi como também $3 \mathrm{~g}$ e $4 \mathrm{~g}$, as falas da Monja Coen podem ser ouvidas em distintos ambientes físicos, como casas, locais de trabalho e transportes públicos, entre outras possibilidades.

É difícil (ou talvez impossível) mensurar com precisão esse impacto, embora se possa perscrutar alguns indícios disponibilizados pelo próprio Youtube: o total de visualizações (até 5 de julho de 2017) dos oitenta e seis vídeos é de 5.001.549, ao passo que a média é de 58.156,5 visualizações por gravação. No entanto, o grau de variação das visualizações é significativo: o vídeo com o menor número contém 6.497, enquanto aquele com maior possui 453.010. De qualquer forma, trata-se de uma quantidade bastante significativa quando comparada a outros youtubers que têm mobilizado parte da opinião pública em diferentes áreas, como é o caso do historiador Leandro Karnal ou do filósofo Mario Sergio Cortella. O caso da Monja Coen é especialmente interessante na medida em que se trata de uma religiosa zen, religião que, como ressaltado, pertencia até recentemente a um repertório étnico nipônico que alguns pesquisadores como Gonçalves (2002) perceberam como num estado de crise. Porém, no momento, o Zen parece transcender essas fronteiras étnicas, espaciais e mesmo religiosas, abarcando públicos não descendentes de japoneses, em diferentes locais do Brasil (e talvez do mundo) e pertencentes a outras religiões. É importante notar que o interesse desses usuários não 
necessariamente volta-se para a conversão, mas, antes, para a apropriação de certos elementos que consideram importantes no discurso da Monja Coen.

No interior do total de vídeos que compõem a série "Monja Coen responde", foram percebidas oito categorias temáticas: 1) "Budismo", 2) "Relações entre religiões", 3) "Relacionamentos interpessoais", 4) "Questões terapêuticas", 5) “Morte", 6) "Problemas sociais", 7) "Sexualidade” e, por fim, 8) “Outros assuntos". $\mathrm{O}$ critério para sua delimitação diz respeito à pergunta fundamental em torno da qual a gravação gira, que é expressa em seu início de forma escrita, sendo enviada pelos internautas. É válido ressaltar que as categorias circunscritas são em parte subjetivas, uma vez que diferentes observadores poderiam enxergar padrões diferenciados. Todavia, como os vídeos em foco compõem uma série mais ou menos numerosa, é possível observar certos padrões fundamentados em repetições temáticas que parecem significativas. Outra questão para a qual é necessário atentar é que as categorias são flexíveis, porquanto certos vídeos possam ser alocados em mais de uma.

A seguir, é realizada a descrição das categorias: 1) "Budismo": foram alocados vídeos (totalizando 24) que versam abertamente sobre assuntos relacionados à religião, tais como karma e Iluminação. Embora todas as gravações em potencial utilizem como base explicativa os princípios budistas, algumas delas versam sobre pontos a princípio diversos, tendo o Zen como pano de fundo; 2) "Relações com outras religiões" (6 vídeos): dizem respeito às discussões sobre as relações entre o Budismo e diferentes religiões, como o Cristianismo e o Espiritismo; 3) "Relacionamentos interpessoais" (7 vídeos): abordam problemas relacionados às relações interpessoais, como amor, paixão e convivência com o outro; 4) "Questões terapêuticas" (17 vídeos): refletem sobre diferentes aspectos de dimensão terapêutica, como medo, ansiedade, controle de si e confiança; 5) "Morte" (3 vídeos): tocam na perda de pessoas próximas, como filhos, ou sobre o destino do ser após o trespasse; 6) "Problemas sociais" (9 vídeos): abarcam uma variedade de problemas de ordem social, como corrupção na política, destruição do meio ambiente e consumismo; 7) "Sexualidade" (2 vídeos): a abordagem recai 
sobre questões como assédio sexual e homossexualidade; por fim, 8) "Outros assuntos (18 vídeos): englobam pontos que apareceram de forma fragmentária e desconexa, sendo difícil agrupá-los em alguma categoria específica.

Não serão analisadas todas as categorias em questão, tendo em vista os limites de um artigo. No entanto, seu delineamento é importante, na medida em que é possível observar como o discurso Zen da Monja Coen envolve uma série de elementos aparentemente distantes do universo religioso budista, como a sexualidade e os problemas sociais, que poderiam passar ao largo de um monge mais distante das questões do mundo. Essa conexão com a sociedade em mudança é um aspecto fundamental na leitura da Monja Coen, já que, num vídeo intitulado “Como manter-se tranquilo diante de influências externas?” (MOVA, 2017d), ela ressalta que as práticas budistas (como a meditação e a busca pela Iluminação) não ocorrem em detrimento da turbulência das influências externas, mas no interior delas, considerando que não há, no Zen, divisão entre o eu e o restante do universo, que devem ser percebidos em sua unicidade. Essa flexibilidade criativa nas representações reconstruídas pela Monja Coen sugerem justamente a dinamicidade histórica de uma religião que, saindo da Índia, passando pela China e pelo Japão e, por fim, sendo trazida do território nipônico para o Brasil, consegue transcender as fronteiras étnicas para alcançar diferentes públicos por intermédio de sua acomodação e ressignificação em variados espaços e tempos.

As duas categorias que aparecem com maior frequência na série "Monja Coen responde” são "Budismo” e “Questões terapêuticas”. No caso da primeira, os internautas levantam desde questões bastante gerais, como "Qual é o essencial para tornar-se budista?” (MOVA, 2017b), até perguntar específicas como “O Nirvana é um estado permanente?” (MOVA, 2016b) ${ }^{12}$. Por um lado, existem indícios de uma curiosidade sobre a religião oriental, enquanto que, por outro, apresenta-se uma indagação de caráter mais profundo, fruto, provavelmente, de usuários mais informados a respeito de discussões budistas. As respostas da Monja Coen são, de

\footnotetext{
12 O Nirvana, assim como a lluminação, é um conceito controverso no interior das diferentes escolas budistas. No Theravâda, ele é interpretado como o estado de libertação do Samsara alcançado após a lluminação do indivíduo, que viveria, então, sua última vida antes de entrar no vazio absoluto (COHEN, 2008).
} 
forma geral, bastante "simples" e acessíveis ao público em geral, dialogando com o Zen e com o Budismo de modo mais amplo, mas sem recair num discurso prolixo e cercado por filigranas acessíveis a apenas alguns iniciados. Isso talvez seja um dos elementos sedutores nos vídeos em questão, justificando sua popularização que se reflete, em parte, no alto índice de visualizações.

De qualquer forma, esse interesse dos usuários pelo Budismo, o que demanda a produções de vídeos para responder tanto às questões gerais quanto às específicas, pode ser explicado por múltiplos canais. Como afirmado, a segunda metade do século XX reflete, em diversos países do Ocidente, incluindo o Brasil, um interesse pelas formas de pensamento oriental como mecanismo para buscar uma religiosidade para além das matrizes judaico-cristãs, por um lado e, por outro, do paradigma mecanicista (WATTS, 1988; ALBUQUERQUE, 1999). Além disso, a presença, em diferentes cidades brasileiras, de templos budistas de matriz japonesa tornou esse mundo oriental mais próximo fisicamente, embora, às vezes, ainda enigmático em razão das fronteiras étnicas ainda bastante demarcadas em algumas vertentes e escolas. A existência de uma monja com capital religioso reconhecido, mas sem ascendência japonesa e que esteja disposta a esclarecer os "mistérios" do Oriente, permite justamente dar vazão a esse desejo de conhecer essa familiaridade ainda algo distante ${ }^{13}$.

A segunda categoria mais popular em termos de número de vídeos, como afirmado, é denominada "Questões terapêuticas". No entanto, é interessante enfatizar que, a despeito de possuir menor quantidade de itens, tratam-se das gravações com número de visualizações bastante alto. Como indicado, a média por vídeo de toda a série "Monja Coen responde" é de 58.156,6 visualizações. Três vídeos da categoria “Questões terapêuticas” excedem em muito a média, tais como "O que pensam sobre você” (207.102 visualizações, MOVA, 2017e), “Aquietar o coração" (212.678, MOVA, 2017a) e, por fim, o caso de maior visualização de toda a

\footnotetext{
${ }^{13}$ É necessária cautela acadêmica para lidar com o Oriente, uma vez que, historicamente, foi criada sobre o Japão uma série de representações ocidentais de caráter exótico, geralmente baseada em imagens como a gueixa e o samurai (DEZEM, 2005). Nesse sentido, pode-se utilizar a concepção proposta por Edward Said (1990) de Orientalismo, isto é, a perspectiva ocidental sobre o Oriente matizada de estereótipos, não obstante o autor aborde o Oriente Médio.
} 
série (e não apenas da categoria): “Amor próprio” (453.010, MOVA, 2016a), que parte da pergunta “Como desenvolver o amor próprio?”.

Os números, aqui, constituem indícios emblemáticos no sentido do que os usuários procuram no Zen. No Brasil, nas últimas décadas, foram desenvolvidas várias ideias em torno das quais a meditação (em diferentes vertentes) seria uma prática fundamental para controlar a ansiedade, o stress, a depressão e o pânico. Inúmeros textos disponíveis na Internet ressaltam essa correlação, citando ou não experiências de pesquisadores que teriam mensurado o estado psicofisiológico de meditadores, principalmente monges, que permaneceriam calmos por meio dessas práticas (BONS, s.d.; TEIXEIRA; PAULI, s.d.; MORAIS, 2003). Tendo em vista a alta incidência de problemas relacionados à ansiedade na sociedade contemporânea, os vídeos disponibilizados pela Monja Coen ofereceriam soluções mais ou menos rápidas para essas questões. Como percebeu Rocha (2002) por meio de entrevistas com praticantes do Zen no Templo Busshinji, alguns deles procuravam o espaço institucional com o intuito de buscar soluções para a inquietude da mente. Pode-se presumir que, por razões diversas, certos usuários que não tenham disponibilidade para frequentar os templos acessem os vídeos para aprender técnicas para combater a ansiedade, apropriando-se, como ressaltado, de aspectos do discurso Zen que melhor atenderiam às suas expectativas.

Feita a categorização da totalidade dos vídeos que compõe a série "Monja Coen responde”, bem como a análise de algumas dessas categorias, é importante, agora, abordar a representação construída em algumas dessas gravações, seja no tocante à estética audiovisual, seja em relação aos conteúdos trabalhados. Foram escolhidos, aqui, dois vídeos: o já citado "Amor próprio" (MOVA, 2016a) e “Contatos paranormais são evidências de consciência após a morte?” (MOVA, 2017c). Trata-se, como visto, de uma pequena amostra se forem contabilizados todos os itens da série. Eles foram selecionados na medida em que parecem sugerir a flexibilidade do discurso Zen produzido pela Monja Coen e, também, pelos editores responsáveis pela linguagem audiovisual das fontes em questão. 
O primeiro vídeo, “Amor próprio” (MOVA, 2016a), possui um padrão de linguagem audiovisual que se repete, com algumas mudanças, em outras gravações. A narrativa se inicia com uma tela inicial em que a pergunta enviada pelo usuário é destacada. No caso, é a seguinte: “Todos os dias leio e ouço dizer sobre amor próprio. Como encontrá-lo para não mais perdê-lo?”. Ao fundo, há uma imagem estática da parte esquerda do rosto da Monja Coen sorrindo em close-up diante de um altar budista desfocado, mas ainda assim reconhecível para o espectador. No decorrer do vídeo, não há corte de cenas; a Monja Coen aparece respondendo à questão olhando diretamente para a câmera, centralizada, tendo ao fundo o mesmo altar da imagem estática, ornamentado com um vaso com flores na parte esquerda e, na direita, uma vela sobre um candelabro. A monja veste um hábito branco e preto, falando em tom de voz calmo, pausado e claro sobre a questão, sempre com um sorriso no rosto. Não há música ao fundo, ouvindo-se apenas, eventualmente, de forma baixa, o som do mundo cotidiano. A cena é exposta à luz criando-se uma leve superexposição, puxando, portanto, o tom para o branco. Ao terminar a fala, a monja faz o gashô e a cena retorna para a tela inicial com sonoplastia de água gotejando aos poucos.

É importante atentar para os elementos de composição da linguagem audiovisual, tendo em vista que não constituem apenas aspectos estéticos, mas atuam também na construção da mensagem em foco. O vídeo pode ser considerado um canal para a criação de representações, utilizando o conceito proposto por Chartier (2002), que remete para a forma como os indivíduos e os grupos criam formas de serem socialmente percebidos, tornando-se objeto de apropriação pelo outro. Deve-se lembrar que os vídeos no Youtube são artefatos culturais voltados para o consumo em escalas variadas por parte dos internautas, sendo fundamental a quantidade de visualizações para definir seu sucesso. Não coincidentemente, o próprio Youtube passa a adicionar propagandas em produções que ultrapassem determinado número de visualizações, havendo, portanto, certo princípio mercadológico no meio, ainda que não necessariamente ligado ao conteúdo do vídeo. 
No vídeo em questão, é construída uma representação segundo a qual a Monja Coen falaria diretamente com o usuário. Como visto, ela olha para a câmera, e não para outro ponto do enquadramento, rompendo com um elemento de composição relativamente comum na linguagem cinematográfica (DUBOIS, 1993). Ao invés de basear-se numa ilusão de realismo que ignoraria a câmera, o olhar voltado diretamente para o dispositivo cria a impressão de que o interlocutor do "diálogo" seria o próprio espectador, num tom intimista que traria a aparentemente distante linguagem do Zen para perto de si. Associada à ilusão de intimidade, pode-se ressaltar a construção de uma monja calma, de fala macia e com um sorriso no rosto. Não se trata dos monges que compõem algumas das anedotas Zen que, ao serem indagados, golpeariam seus discípulos com o bastão na cabeça (SUZUKI, 2005). Aqui, por outro lado, a Monja Coen é envolta numa aura de plenitude esperada por um público não budista, dando conselhos serenos para aqueles que teriam dúvidas, assumindo, portanto, a representação ocidental do sábio. A quietude é completada pela ausência de músicas, havendo a sonoplastia de água gotejando calmamente apenas ao final do vídeo. Aliás, o "silêncio" pode ser emblemático no repertório Zen, remetendo para aspectos sobre os quais não se atenta no cotidiano: o cantar dos pássaros, o motor dos carros e o ladrar dos cães. Não casualmente, o compositor norte-americano John Cage, sob influência do Zen, executa recitais em que, apesar dos músicos e dos instrumentos a postos, não se toca nada, permitindo que o público atente para os sons a princípio imperceptíveis do ambiente (WATTS, 1988).

Outro elemento de composição visual para o qual é importante atinar diz respeito à iluminação da cena, que se inclina para a superexposição em detrimento de um balanço mais equilibrado entre luzes e sombras. Isso, em primeiro lugar, contribui para o desenvolvimento da representação do sábio: no Ocidente, de forma maniqueísta, a sombra tem sido ligada a ideias como ignorância, retrocesso ou mesmo ao mal; por outro lado, a luz seria a fonte de sabedoria, avanço e do bem, recordando que essa dicotomia tem sido utilizada tanto pelo discurso religioso quanto pelo imaginário racionalista, como é o caso do Iluminismo (ANDRÉ; SILVA, 2012). Retornando ao vídeo, a cena amplamente iluminada também pode 
remeter, como corolário da primeira questão, a uma representação da Iluminação budista literalmente envolta em luzes. No filme "Zen", dirigido por Banmei Takahashi (2009), ao iluminar-se, o Monge Dôgen seria elevado sobre uma flor de lótus, durante a meditação, para um céu claro. Não é impossível, no caso dos vídeos postados no canal MOVA, que haja certa interlinguagem em relação à representação da Iluminação em diferentes obras, ocidentais ou orientais. Aqui, o vídeo situa-se no cenário budista, arquitetado também a partir da própria monja, de cabeça raspada e trajando o hábito monástico, falando diante de um altar com velas e flores. Isto é, tanto a personagem quanto o local desempenham o papel de signos com o intuito de tentar enquadrar a leitura dos usuários.

Como visto, a linguagem audiovisual não desempenha papel secundário, auxiliando, antes, na construção da mensagem em foco. O discurso da monja, como afirmado, parte do tema "amor próprio". Diante da pergunta, a monja ressalta que a autovalorização depende de uma série de variáveis, incluindo-se as experiências vividas pelo indivíduo em fases como a gestação, o nascimento e a tenra infância, citando, inclusive, o caso de seus cães quando filhotes, que teriam recebido muito ou pouco afeto. Sem utilizar a palavra karma, Coen envereda pela interpretação budista, afirmando que as vivências anteriores seriam fundamentais na medida em que o ser atual seria fruto do conjunto de ações ao longo do tempo, estando todos num processo contínuo de transformação em que não haveria perfeição num porvir, mas no devir. Ela encerra a fala com o gashô, que também desempenha o papel de signo budista que auxilia o espectador a situar o discurso no universo zen.

O discurso da Monja Coen é arquitetado de forma significativa. Por um lado, parte de uma questão de fundo terapêutico, versando sobre o amor próprio; por outro, o repertório utilizado para fazê-lo é o pensamento Zen, que aparece de modo sutil e estratégico. Ao invés de recair em difíceis explicações sobre o karma, que poderia dificultar a compreensão por parte de um público não iniciado no Budismo, a monja utiliza o princípio por meio de explicações relativamente simples, fundamentadas em exemplos (como dos cachorrinhos) e de forma bastante acessível. Outro elemento trabalhado, corolário do primeiro, diz respeito à 
impermanência do ser, o Samsara, também não citado conceitualmente. Ele seria marcado, na fala de Coen, por contínuas transformações ao longo do tempo. Do mesmo modo, o Samsara é explicado de maneira suave e exemplificada, concluindo-se que a perfeição seria encontrada no processo de mudança e não em algum ponto específico. O discurso da monja parece cumprir as expectativas do público ao versar sobre questões de fundo terapêutico sem se ancorar num repertório religioso prolixo e distante, o que parece explicar a alta quantidade de visualizações desse vídeo, batendo o recorde do canal.

Outros vídeos, contudo, abordam a questão religiosa de forma mais profunda, especialmente aqueles que se situam na categoria "Relações com outras religiões". Um deles é aquele intitulado "Contatos paranormais são evidências de consciência após a morte?”. A linguagem audiovisual, de forma geral, é padronizada em todas as gravações, sugerindo, como afirmado, representações voltadas para o tom intimista do sábio iluminado e sereno que falaria diretamente com o público. Apenas alguns aspectos variam em relação ao padrão composicional, tais como o fundo da tela inicial ou o hábito utilizado pela monja que, no caso, é dourado.

No caso do vídeo em questão, a pergunta que aparece na tela inicial é bastante direcionada:

Os contatos paranormais como o do Medium Chico Xavier, que não deixam dúvidas da veracidade, seriam contatos com uma consciência ou mente póstuma do ser (já que inexiste espírito, alma etc.)? Seria uma evidência de que existe uma transformação também da mente após o que se chama morte, e não somente do corpo?

Diante da pergunta norteadora, a monja não nega a mediunidade de Chico Xavier, afirmando que se trata de um fato. Inclusive, durante a gravação, o telefone toca e ela brinca que as pessoas querem fazer contato. No entanto, Coen problematiza o que constitui a vida e a morte, ressaltando que é difícil defini-las e separá-las com precisão, inclusive do ponto de vista biológico. Para desenvolver a resposta, ela cita uma série de autores, desde o literato colombiano Gabriel García Márquez ao psicoanalista suíço Carl Gustav Jung. Assim como no vídeo anterior, a 
monja chama a atenção para o fato de que a vida dos seres estaria imersa num ciclo de transformação, citando uma ideia de Dôgen segundo a qual, uma vez queimada, a brasa não volta a ser lenha, assim como a cinza não volta a ser brasa.

O vídeo como um todo é bastante complexo. Em primeiro lugar, no que diz respeito à pergunta norteadora, o usuário opta por uma questão direcionada e não necessariamente aberta, afirmando que a mediunidade do espírita mineiro Chico Xavier seria um fato sem dúvida de veracidade. A monja, nesse sentido, não nega a diretiva, mas a problematiza de diferentes formas. Pode-se presumir que não se trate de uma resposta espontânea (ainda que a espontaneidade quanto ao telefone que toca seja notável), uma vez que, possivelmente, as perguntas abordadas na série "Monja Coen responde" seriam selecionadas para a elaboração dos vídeos. Isso em si implica em diferentes representações nos vídeos, na medida em que nem todas as questões tornam-se objeto de reflexão, provavelmente em razão de sua quantidade significativa, considerando que são coletadas nas redes sociais.

Em segundo lugar, o usuário que levanta a questão sobre a mediunidade possui certo conhecimento acerca do Budismo, tendo em vista que ressalta a questão da inexistência do espírito. Em certas vertentes e escolas budistas, embora se fale de renascimento, o que renasceria não seria necessariamente o "espírito", concebido como real, essencial e imortal (atman), mas a ilusão de individualidade derivada da ignorância produzida pelos sentidos (anatman) (COHEN, 2008; DALAI LAMA, 2011). Diante da pergunta, a Monja Coen afasta-se sutilmente de uma noção reencarnacionista, enfatizando, novamente, uma concepção de Samsara fundamentada no processo de transformação inerente ao ser, que pode envolver a vida e a morte, mas que se realiza a todo o momento. Portanto, continuamente os indivíduos estariam morrendo e renascendo, posto que mudando, daí sua afirmação ao fim do vídeo: "renasça, não reencarne” (MOVA, 2017c).

Embora o Zen seja uma escola budista, ele tende e distanciar-se do princípio reencarnacionista comum, por exemplo, no Budismo tibetano, tendo em vista, por exemplo, que o Dalai Lama seria considerado o décimo quarto renascimento do 
mais alto tulku tibetano (DALAI LAMA, 1992). Ao invés de interpretar o Samsara como ciclo de mortes e renascimentos, para o Zen ele aconteceria em cada filigrana do tempo. O próprio R. M. Gonçalves (2002) afirma que, em seus primeiros contatos com o Zen durante a juventude, tentava compreender a religião por intermédio do repertório espírita, influência da mãe. No entanto, os monges estranhavam essa leitura, voltando-se para o Samsara enquanto ciclo que ocorreria em vida, ainda que a morte continue desempenhando papel importante entre os zen budistas.

Retornando ao vídeo sobre a mediunidade, aparece outro elemento importante no discurso da Monja Coen a respeito do diálogo entre as diferentes religiões. Embora ela própria participe de variados encontros inter-religiosos, como fica claro nas informações disponibilizadas em seu site (MONJA COEN SENSEI, s.d.), Coen não costuma interpretar as personagens, as concepções e as práticas de religiões diferentes em termos budistas. Portanto, ao invés de afirmar que o princípio reencarnacionista do Espiritismo poderia ser enquadrado no Samsara do Zen, a monja problematiza a questão da vida e da morte, mantendo a interpretação no terreno zen budista. Diferentemente do vídeo anterior, em que os problemas de ordem terapêutica são apropriados sem maiores problemas no repertório zen, ainda de que de forma sutil, na categoria "Relações com outras religiões”, malgrado o diálogo religioso apareça, os elementos de religiões como o Espiritismo ou o Cristianismo não são reduzidos ou alinhavados ao sistema zen.

Os vídeos aqui analisados constituem apenas uma pequena amostra, como afirmado, da totalidade de produções que compõe a série "Monja Coen responde". De qualquer modo, percebe-se, tanto pelas categorias elencadas quanto pelas gravações abordadas, que a monja estabelece um diálogo não circunscrito ao universo budista propriamente dito. São feitas relações com diversos aspectos do mundo contemporâneo, tais como as interfaces com outras religiões e com as questões de caráter terapêutico. As visualizações permitem perceber alguns indícios referentes ao interesse do público pelas discussões realizadas pela monja, concentrando-se principalmente nas reflexões de ordem terapêutica, em 
consonância com as observações realizadas por Rocha (2002) no tocante aos praticantes de zazen no Templo Busshinji. Os vídeos, de forma geral, constroem representações da monja a partir da figura do sábio, detentor não apenas de conhecimento intelectual, mas de uma sabedoria que pode ser comunicada de maneira serena e intimista, falando "diretamente" com o espectador. Percebeu-se a ênfase em discussões terapêuticas, mas também num diálogo inter-religioso que envolve dimensões como o Espiritismo e o Cristianismo. Porém, nessa aventura pelo universo do sagrado, Coen busca não enquadrar a religião do outro no Budismo, não transformando figuras como Chico Xavier e Jesus Cristo em budas fora do dharma.

\section{Conclusão}

Os vídeos da Monja Coen postados no canal MOVA inserem-se no movimento de constituição de uma cyber sangha, como atentou Rocha (2002) em seu texto sobre os praticantes de zazen no Templo Busshinji. Isso implica não apenas numa modificação dos meios de comunicação com os potenciais praticantes, saindo dos espaços físicos e adentrando nos meios virtuais. A migração de mídia permite alcançar um número maior de interessados em assuntos relacionados ao Zen, adeptos ou não do Budismo, e que o procuram com múltiplos fins, desde conhecer a visão da religião oriental sobre a mediunidade até obter respostas para lidar com problemas de natureza terapêutica. O diálogo cultural torna-se mais amplo, transcendendo as fronteiras étnicas de um Budismo de imigração, como apontado por Usarski (2002). São englobados tópicos como relações inter-religiosas, terapia e sexualidade, constituindo mais que um Budismo de conversão (USARSKI, 2002), mas um Budismo de conveniência, no qual alguns de seus elementos são apropriados de acordo com os interesses específicos dos praticantes. Budistas ou não, esses adeptos/usuários procuram servir-se do multifacetado universo religioso contemporâneo, o que Rocha (2002, p. 239) denomina de um Budismo pick and mix voltado para a construção de uma prática espiritual de cunho particular. 
Nesse sentido, o cyber Zen praticado pela Monja Coen nos vídeos do Youtube seria uma das respostas contemporâneas relativamente bem sucedidas no que se relaciona à chamada "crise" do Budismo de imigração, tal como percebida por autores como Usarski (2002) e Gonçalves (2002). O fenômeno, portanto, embora pareça estar situado num presente imediato, considerando que a série "Monja Coen responde" possui apenas dois anos, insere-se no processo histórico de acomodação de uma religião a princípio étnica no Brasil que remonta aos primeiros imigrantes japoneses vindos para o país a partir de 1908. Com o envelhecimento e a morte da primeira geração, paralelamente à falta de condições para a preservação da língua japonesa nas esferas pública e privada, as diferentes escolas budistas começaram a buscar formas de expandir-se entre não descendentes de japoneses como mecanismo de sobrevivência. Algumas delas, como as escolas de Terra Pura, ainda permanecem demasiadamente étnicas (ANDRÉ, 2016; LUIZ, 2017); outras passaram a investir em formas de proselitismo mais dinâmicas, formando um clero nativo e divulgando os ensinamentos da religião em português, como é o caso da Monja Coen. Assim, a impermanência budista, considerando o caso do Zen, parece também se enredar nos fios luminosos da Web.

\section{REFERÊNCIAS}

ALBUQUERQUE, Eduardo Basto de. O Mestre Zen Dôguen. São Paulo: Arte \& Ciência, UNIP, 1997.

ALBUQUERQUE, Eduardo Basto de. Um mestre zen na terra da garoa. In: USARSKI, Frank (Org.). O Budismo no Brasil. São Paulo: Editora Lorosae, 2002. p. 151-170.

ALBUQUERQUE, Leila Marrach Basto de. Seicho-no-ie do Brasil: agradecimento, obediência e salvação. São Paulo: Annablume, 1999.

ANDRÉ, Richard Gonçalves. Entre a casa, o túmulo e as cinzas: permanências e transformações do culto budista aos ancestrais entre nipo-brasileiros. Religare, v. 13, n. 2, p. 445-479, 2016.

ANDRÉ, Richard Gonçalves. Religião e silêncio: representações e práticas mortuárias entre nikkeis em Assaí por meio de túmulos (1932-1950). Assis, 2011. 25of. Tese (Doutorado em História) - Faculdade de Ciências e Letras, Universidade Estadual Paulista. 
ANDRÉ, Richard Gonçalves; SILVA, Ana Cristina Teodoro da. Click... ou bang? Imagens da morte na historiografia sobre a fotografia. Domínios da imagem, Londrina, v. 10, p. 31-41, 2012.

AZEVEDO, Murillo Nunes de. Zen-Budismo: o caminho direto. In: SUZUKI, D. T. (Org.). Introdução ao Zen Budismo. 10. ed. Tradução Murillo Nunes de Azevedo. São Paulo: Editora Pensamento, 2005. p. 33-45.

BONS FLUIDOS DIGITAL. Contra a ansiedade e o estresse - parte 2. s.d. Disponível em:<http://bonsfluidos.uol.com.br/noticias/bem-estar/contra-a-ansiedade-e-o-estresse--parte-2.phtml\#.WWkRvoTyvIV>. Acesso em: 14 jul. 2017.

BOURDIEU, Pierre. A economia das trocas simbólicas. 6. ed. São Paulo: Perspectiva, 2005 .

BUDISMO da Terra Pura: um guia. São Paulo: Comunidade Budista Sul Americana da Escola Jodo Shinshu Honpa Hongwanji, 2013.

CERTEAU, Michel de. A invenção do cotidiano: artes de fazer. 22. ed. Petrópolis: Vozes, 2014.

CHARTIER, Roger. À beira da falésia: a História entre certezas e inquietude. Porto Alegre: Editora UFRGS, 2002.

COHEN, Nissim. Ensinamentos do Buda: uma antologia do cânone páli. São Paulo: Devir Livraria, 2008.

DALAI LAMA. Liberdade no exílio: uma autobiografia do Dalai Lama do Tibet. São Paulo: Siciliano, 1992.

DALAI LAMA. O caminho do meio: fé baseada na razão. São Paulo: Gaia, 2011.

DEZEM, Rogério. Matizes do "amarelo": a gênese dos discursos sobre os orientais no Brasil (1878-1908). São Paulo: Associação Editorial Humanitas, 2005.

DUBOIS, Philippe. O ato fotográfico e outros ensaios. 7. ed. Campinas: Papirus, 1993.

ESSELIN, Fernando. A monja é pop. Revista Cláudia, São Paulo, ano 56, n. 667, p. 114117, abr, 2017.

FLEURY, Lipe; Mova Filmes. Coen: 35 anos de vida monástica. 2017. Vídeo do Youtube (29:58): sonoro, colorido, áudio em português. Disponível

em:<http://www.youtube.com/watch?v=B9gjHdoKcXM>. Acesso em: 15 maio, 2018.

GONÇALVES, Ricardo Mário. A religião no Japão na época da emigração para o Brasil e suas repercussões em nosso país. In: O japonês em São Paulo e no Brasil. Centro de Estudos Nipo-Brasileiros, São Paulo, p. 58-73, 1971.

GONÇALVES, Ricardo Mário. A trajetória de um budista brasileiro. In: USARSKI, Frank (Org.). O Budismo no Brasil. São Paulo: Editora Lorosae, 2002. cap. 7, p. 171-192. 
GONÇALVES, Ricardo Mário. Considerações sobre o culto de Amida no Japão medieval: um exemplo de consciência histórica no Budismo japonês. São Paulo, 1975. 172f. Tese (Doutorado em História) - Faculdade de Ciências e Letras, Universidade de São Paulo.

HOBSBAWM, Eric. Introdução: a invenção das tradições. In: HOBSBAWM, E.; RANGER, Terence (Org.). A invenção das tradições. 9. ed. São Paulo: Paz e Terra, 2014. p. 7-25.

LUIZ, Leonardo Henrique. Acomodação e perpetuação do Budismo de Terra Pura em Londrina. Londrina, 2017. Trabalho de Conclusão de Curso (Graduação em História) - Centro de Letras e Ciências Humanas, Universidade Estadual de Londrina.

MAEYAMA, Takashi. O imigrante e a religião: estudo de uma seita religiosa japonesa em São Paulo. São Paulo, 1967. Dissertação (Mestrado em Antropologia) - Faculdade de Filosofia, Letras e Ciências Humanas, Universidade de São Paulo.

MATSUE, Regina Yoshie. O Budismo de Terra Pura em Brasília. In: USARSKI, Frank (Org.). O Budismo no Brasil. São Paulo: Editora Lorosae, 2002. cap. 8, p. 193-219.

MOHERDAUI, Bel. A estrela do zen-ativismo. Veja, São Paulo, n. 1939, 18 jan. 2006.

Monja Coen fala sobre a felicidade que traz o autoconhecimento. Mais você, Rede Globo, 9 jan. 2017.

MONJA, Coen Sensei, s.d. Disponível em:< http://www.monjacoen.com.br/>. Acesso em: 14 jul. 2017.

MONJA, Coen. Provocações. Rede Cultura, 2016.

MORAIS, Jomar. É só respirar. Super interessante. 2003. Disponível em:<http://super.abril.com.br/ciencia/e-so-respirar/> . Acesso em: 14 jul. 2017.

MOVA. Amor próprio. 2016a. Vídeo do Youtube (3:09): sonoro, colorido, áudio em português. Disponível em: < http://www.youtube.com/watch?v=4hITKU4pthM >. Acesso em: 15 maio. 2018.

MOVA. Aquietar o coração. 2017a. Vídeo do Youtube (2:40): sonoro, colorido, áudio em português. Disponível em: < http://www.youtube.com/watch?v=wk4UklwewJU >. Acesso em: 15 maio. 2018.

MOVA. Auto-denominar-se budista. 2017b. Brasil. Vídeo do Youtube (1:56 min.): sonoro, colorido, áudio em português. Disponível

em:<http://www.youtube.com/watch?v=eq6Uoxipz6o > . Acesso em: 15 maio. 2018.

MOVA. Contatos paranormais são evidências de consciência após a morte? 2017c. Vídeo do Youtube (6:14): sonoro, colorido, áudio em português. Disponível em:<http://www.youtube.com/watch?v=vwozOMEvneY>. Acesso em: 15 maio. 2018. 
MOVA. Influências externas. 2017d. Brasil. Vídeo do Youtube (2:50 min.): sonoro, colorido, áudio em português. Disponível

em:<http://www.youtube.com/watch?v=AtH4rj-gGPo>. Acesso em: 15 maio. 2018.

MOVA. Nirvana. 2016b. Brasil. Vídeo do Youtube (1:09 min.): sonoro, colorido, áudio em português. Disponível em: <http://www.youtube.com/watch?v=eiMg8cWNsow>. Acesso em: 15 maio. 2018.

MOVA. O que pensam sobre você. 2017e. Vídeo do Youtube (3:20 min.): sonoro, colorido, áudio em português. Disponível

em:<https://www.youtube.com/watch?v=DwIWSnT1cvg>. Acesso em: 15 maio. 2018.

NAKAMAKI, Hirochika. A Honmon-Butsuryû-Shû no Brasil: através de registros do Arcebispo Nissui Ibaragui. In: USARSKI, Frank (Org.). O Budismo no Brasil. São Paulo: Editora Lorosae, 2002. cap. 3, p. 73-105.

NAMU. Meditação zen-budista. 2014. Vídeo do Youtube (8:03 min.): sonoro, colorido, áudio em português. Disponível em: $<$ http://www.youtube.com/watch?v=r_oozyhRYQU>. Acesso em: 15 maio. 2018.

NAPOLITANO, Marcos. Fontes audiovisuais: a História depois do papel. In: PINSKY, Carla Bassanezi (Org.). Fontes históricas. 3. ed. São Paulo: Editora Contexto, 2011. cap. 7, p. 235-289.

NOVAES, Marina. Monja Coen: “A corrupção está dentro de nós”. El País, 3 mai. 2016. Disponível em:<https://brasil.elpais.com/brasil/2016/o4/28/politica/1461874978_938192.html>. Acesso em: 14 jul. 2017.

O EU MAIOR. Direção de Fernando Schultz e Paulo Schultz. Estúdio: Associação Dobem. 2012. Filme (90 min.): sonoro, colorido, áudio em português.

ROCHA, Cristina Moreira da. Se você se deparar com Buda, mate Buda! - reflexões sobre a reapropriação do Zen-Budismo no Brasil. In: USARSKI, Frank (Org.). O Budismo no Brasil. São Paulo: Editora Lorosae, 2002. cap. 9, p. 221-251.

SAID, Edward W. Orientalismo: o Oriente como invenção do Ocidente. São Paulo: Companhia das Letras, 1990.

SEKIDA, Katsuki. Za zen. 4. ed. Barcelona: Editorial Kairós, 2008.

SUZUKI, Daisetz Teitaro. Introdução ao Zen Budismo. 10. ed. São Paulo: Editora Pensamento, 2005.

SUZUKI, Teiti. The Japanese immigrant in Brazil. Tokyo: University of Tokyo Press, v. $1,1969$.

TEIXEIRA, Larissa; PAULI, Paula Ragazzi. 6 formas de combater a ansiedade sem remédios. Focas. s.d. Disponível em:<http://infograficos.estadao.com.br/focas/tantoremedio-para-que/mente-5.php>. Acesso em: 14 jul. 2017. 
USARSKI, Frank. O Budismo no Brasil: um resumo sistemático. In: USARSKI, F. (Org.). O Budismo no Brasil. São Paulo: Editora Lorosae, 2002. cap. 1, p. 9-33.

VALLERIO, Ciça. Uma budista do balacobaco. O Estado de São Paulo, 11 dez. 2009. Disponível em:<http://emais.estadao.com.br/noticias/geral,uma-budista-dobalacobaco,480590>. Acesso em: 14 jul. 2017.

WATTS, Alan. O Zen e a experiência mística. São Paulo: Cultrix, 1988.

ZEN. Direção de Banmei Takahashi. Estúdio: The Buddhist Film Foundation. 2009. Filme (127 min.): sonoro, colorido, áudio em japonês. 